is due. Only when this is white has the proper colour of the water a full chance of manifesting itself. From the heights of Capri I noticed that the shallow water near the shore showed decidedly green, an effect attributed to the yellowness of the underlying sand.

\section{A GEOLOGIC FORECAST OF THE FUTURE OPPORTUNITIES OF OUR RACE.'}

THE established custom of occasions of this kind leads the association to expect that its retiring president will address it upon some theme connected with the field of his own work. I shall not altogether ignore this custom, but I have chosen a theme that is at once peculiarly humanistic and distinctly prophetic. Geology has not usually been regarded as in any special sense a humanistic science, much less a prophetic one. But it is just because it has not been so regarded, and because I have fondly dreamed that it might become tributary in an eminent degree to humanistic problems and to a prophetic insight, that $I$ have chosen the theme assigned for the evening.

Ever since the race came to a virile state of intelligence, it has tried to peer into the future that it might guide itself by its foresight. Now and then it has prolonged its vision beyond mere temporary concerns, and has endeavoured to prophesy the end of the race and the destruction of the earth. At all stages the depth of its vision into the things before has been close akin to the length of its vision backward and to the depth of its insight into the things about it. The lamp of the past and the illumination of the present have been its light for the future. This must doubtless always be its true method, for only as the race sees far into the past, sees widely and deeply into the present, has it any firm basis for a confident prophecy of the future. Even in its early days, the race did not fail to note that-though this may not be so of the ultimate entities - the existing forms come into existence, live their day, and pass away; why not, therefore, the race and the earth on which it dwells? Even as the race grows into its fuller maturity and the horizon of its vision is enlarged, there will doubtless still remain the conviction that there has been a beginning of the current order of things, and a like conviction that there will be an end. The enlargement of vision will only serve to bring into view an additional multitude of organisms and organisations that have come into form, endured for a time, and passed away. Any future change in human forecasts is not likely to be one of method, but one of measure. Some of the features that have entered into former prophecies will no doubt diszppear, and perhaps new ones be added. The forecasts of pre-scientific times often made the doom of the earth hinge on some lapse in the conduct of man-made a physical disaster serve as a moral punishment. With a better knowledge of the moral law and of man's place in nature, this anthropic view will no doubt give place to a morc consistent insight into the sequences of the moral and the physical worlds.

In the earlier days of the race the backward look was short, and the putative origin of the race and of the earth was placed but a few thousand years in the past; in consonance with this, the forward look placed the end not far in the future. So, too, as the beginning was made chaotic, the end was made cataclysmic.

The dawn of the earth sciences was followed by a new forecast, and as these sciences grew this underwent revisions and recasts. It was learned that the history of the earth stretches back not merely for thousands but for millions and tens of millions of years; that the on-goings of the earth are actuated by energies too broad and deep and strong to be swerved in their course or brought to an end by the acts of those who dwell upon it; that the march of earth-history has a mighty tread not to be measured by the merits or lapses of even our favoured race.

The trend of prophetic thought in the last century invites a closer review. The basis of forecast lay fundamentally in the mode of origin assigned the earth and in the general trend of its past history, especially the trend of those

1 Address delivered at Boston, Mass., on December 27, 1909, by the retiring president of the American Association for the Advancement of Science, Prof. T. C. Chamberlin. agencies that controlled the conditions of life on its surface. The solar system was thought to have had its origin in a gaseous or quasi-gaseous nebula. The earth, as a member of the solar system, partook of this origin, and was conceived to have been, at an early stage, itself a fiery, gaseous globe. It is not needful here to review the special hypotheses or pay honour to their great authors from Kant and Laplace to Lockyer and Darwin, for the sole feature that potentially shaped the history of the earth was the early gaseo-molten state in which they essentially concurred. An alternative was, indeed, offered in the suggestion that the earth might have grown up by the accretion of small bodies, but it was then held by students of dynamics that such an origin was inconsistent with the symmetry of the system and the rotations of the planets, and so an origin in the gaseous or quasi-gaseous form was almost universally accepted, as by compulsion. Later, the gaseous earth, by cooling and condensing, was thought to pass into a molten sphere wrapped in a hot, vaporous atmosphere. This atmosphere was vast because the conditions required it to contain all the water of the globe and all the volatile matters that have since entered into the waters and the body of the earth. At a later stage a crust was logically made to form over the molten sphere, and the waters to condense upon it, swaddling the entire globe, perhaps, in it universal ocean. By further cooling, shrinkage, and deformation, the waters were thought to be drawn into basins, the land to appear, and the history of the stratigraphic record to begin. It is important to note that the main agency in this hypothetical history was loss of heat; and so, with consistent logic, loss of heat was made to lie at the bottom of the great events of the earth's subsequent history, and, in the forecast, to be the chief cause of its doom. From a plethora of heat, of air, and of occan, putative loss followed loss in the past, and by prophecy loss is to follow loss in the future until emaciation, drought, and frigidity mark the final state and the end of all life.

As the body of the earth cooled and shrank and permitted penetration, the ocean was made to enter it, and, by union with its substance, was thought to have been suffering loss in the long past and to be doomed to further losses yet to come. By a like union of the constituents of the air with the body of the earth, as time went on, the sreat smothering atmosphere of the primitive days was suppos:d to be brought down first to compatibility with marine life, later to the lower land life, and still later to the higher air-breathing forms.

Projected logically into the future, still further depletion of the vital constituents, even to the verge of exhaustion, attended with pauperisation and finally with extinction of life, entcred into the forecast. With the gathering of the oceans more and more into the basins, and their absorption into the body of the earth, with the persistent consumption of the atmosphere, and with the progressive cooling of the whole, the moisture of the air was thought also to have grown less and less. At first a deep, warm mantle of vapour and cloud hypothetically clothed the whole earth, and even half-way down the geologic ages was thought to have enshrouded the globe and to have given warm, sultry climates to all latitudes. But this mantle at length was made to give place to rifted clouds and clearer skies, and later on to mild aridities, followed at length by desert stages, which are even now supposed to be creeping out persistently on the once fertile lands. Thus we reach our own times at a putative stage when heat and air and moisture are running low; thus the predestined end is foreshadowed in the not distant future.

The round conception of the history shaped it as a progress from excess to emaciation, a sliding down the scale: it made the life-history but an episocie intercurrent in the great decline from the too hot and the too much to the too cold and the too little.

The logic in all this is plausible. Starting with the hypothetical premises, the conclusions seem to follow. Variations of detail might well be found in the complexities of the case. Especially might sources of supply be assigned to offset waste and loss in some degree, but, granting the premises, the conclusion is not easily escaped. In point of fact, the reneral conception dominated the geologic thought of the last century. Not only this, but in no small degree it gave direction to the interpretations, and 
in some measure even influenced the observations of geologic phenomena well down to the close of the century, and is far from obsolete to-day.

But, logical and plausible as was this general conception of earth-history, it was hung, as you have not failed to notice, on the hypothesis of the genesis of the earth accepted. However logical, its logical strength was only that of the hypothesis on which it was hung. I say its logical strength advisedly, for outside the logic of the general concept there was always the appeal to the concrete evidences of the geologic record. This appeal was made, and was thought to be on the whole confirmatory. The strata of high latitudes were found to contain relics of life of tropical or subtropical types, not only in the early stages, but well down toward recent times. Figs and magnolias grew in Greenland as late as the Tertiary period. Phenomena so striking gave deep hold to the logical scheme. Phenomena not so consonant with it were easily overlooked or lightly passed by, as is our wont when too much impressed by what must be true. It is, however, a merit of modern science that it puts that which is to the front, and that which logically must be in a secondary place; and so, during the past century, inconsonant data were gathered with the consonant. Most of the inconsonant facts were of the unobtrusive sort, but yet some of them were startling, were seemingly incredible, were indeed long doubted, and only slowly gained credence. The accumulation of this inconsonant data gradually weakened the hold of the gencral logical concept and prepared the way for a reconsideration.

Meanwhile a serious source of doubt had arisen on the logical side, from the progress of physics. The older hypotheses of the origin of the earth had been framed before the kinetic theory of gases was evolved. After the kinetic view was accepted, it was pointed out by Johnstone Stoney that the velocities of the molecules of the outer air place a limit to the volumes which planetary atmospheres may possess. When the test which this suggested was applied to the postulated atmospheres and voluminous gaseous states of the early earth, it gave rise to grave doubt as to the physical consistency of these conceptions.

Weakness also arose in another quarter. One of the main props of the gaseous or quasi-gaseous hypotheses was, as already remarked, the general conviction, based on dynamical grounds, that condensation from any other nebulous state than the gaseous or quasi-gaseous would give revolutions and rotations to the planetary system at variance with those actually possessed. A re-examination, however, near the close of the century, developed grounds for the conviction that a gradual gathering in of matter from a scattered orbital state would give rotations and revolutions quite as well in accord with the facts formerly known, and seemingly even better in accord with new facts recently brought to light.

Thus toward the close of the last century there arose from different quarters cogent reasons for a reconsideration of the prevailing general view, and with it a recast of the former forecast. Further scrutiny added new doubts to those that had previously arisen, and in the end the verity of the older hypotheses of genesis was challenged, and new conceptions, based on orbital dynamics, in contrast to gaseous dynamics, were offered in their stead.

It is not appropriate for me to say that this challenge was successful, or that the older conceptions of the earth's origin are to be laid on the shelf. As an advocate of the method of multiple. working hypotheses, it belongs to me to beg of you to save and to use, so far as you can find use in them, all the hypotheses that seem to you to be capable of working at all. Much less would it be appropriate for me to affirm that any form of the newer conceptions is entitled to take the place of the older in your complete confidence. The final adjudication of genetic hypotheses can only come of long and patient trial by searching analysis, by scrutinising logic, and by application to the multitudinous phenomena which the earth, not only, but the solar and stellar systems, present. It is sufficient warrant for the present review, however, that not a few of the more incisive students of these things have been led seriously to reconsider the foundations of the hypothesis of earth-genesis that have been offered, old and new, and to examine with renewed care the interpretations and inferences that have been made to hang upon them. Whatever may be your personal leanings, you will, no doubt, agreo that it seems less laudable now to hang prophecies of the future upon hypotheses of genesis than when certain cf these hypotheses received the almost universal assent of those then best qualified to hold opinions respecting them.

It does not seem to be going too far, moreover, to say that, whereas we seemed to be shut up to hypotheses of genesis that gave the earth a gaseo-molten state at the start, it now seems, to some students at least, possible that the earth inherited a quite different state from a slow growth from planetesimal or other accretions. If diverso views are thus permissible, they offer alternative workin: conceptions, and thus help to give freedom of interpretation while they stimulate observations on the critical phenomena. We may, therefore, be permitted first to review the states assigned the early earth by the competitive genesis offered, and then the critical phenomena that bear upon the earth's future.

Quite in contrast with the older pictures of a primitive earth cooling from a gaseous state, the planetesimal hypothesis, which may be taken as representative of theories based on concentration from a dispersed orbital state, postulates a solid earth growing up slowly by accessions, and becoming clothed gradually with an atmosphere and a hydrosphere. Each of the fundamental parts, the earth, the air, and the water, is made to grow up thus together from smaller to larger volumes without necessarily attaining at any stage a very high temperature. The early sources of growth for the atmosphere and the ocean, though reduced in later time, continued to serve as sources of replenishment when the familiar agencies of loss came into play in the later ages. Thus, far from assigning at the start a vast atmospheric and oceanic supply, and assuming progressive depletion of this with the progress of time, the newer view starts with a minimum supply and rests on means of feeding which are held to run hand in hand with the sources of loss and more or less completely to compensate them in a varying way. The question of the future under this view is, therefore, not how long beyond the present day will the original supply last, but rather how long will the oscillating compensation of loss and supply remain effective? Or, in other words, how long will the past degree of equilibrium between the opposing agencies keep the critical conditions within the limits required by life? This question turns us quite away from any serious dependence on the original states, and centres attention on the geologic record and on the potency of agencies still in action. Are the chief agencies which have controlled life conditions for tens of millions of years past still in good working order and likely to continue effective for a long era yet to come, or do they show clear signs of declining power portending an early failure? Let us enter a little closer into the consideration of the specific factors on which life depends, though time will not permit us to go far.

The pre-scientific fear that the end of life will come by cataclysm is not yet obsolete, nor is it theoretically inipossible, but violent agencies are among the least to be feared. Life might, indeed, be imagined to be in jeopardy from volcanic and seismic convulsions, but they really offer no serious menace to life in general, and appear never to have done so in the known ages. The deadliness of these boisterous catastrophes impresses itself unduly on the emotions. The real peril, if peril there be, lies in the deadly unbalancing of agericies of the quiet sort.

The conditions essential to the maintenance of the habitability of the earth are many, but the more critical factors either lie in the atmosphere itself or are intimately associated with it. The point of keenest interest is the narrowness of range to which these mobile factors are confined. The several constituents of the atmosphere might each or all easily be too scant or too abundant. In a peculiar sense is this true of the carbon dioxide, which, though one of the least, is pre-eminently the decisive constituent of the atmosphere. A small proportion of carbon dioxide is essential to plant life, and so to animal life, while a large proportion would be fatal to air-breathing animals. If the three or four hundredths of one per cent now present were lost, all life would go with it; if it were increased to a few per cent., the higher life would te suppressed or radically changed; and vet, on the one hand, the theoretical sources of supply are abundant, while, 
on the other, the agencies of depletion are efficient and active. There is little escape from the conclusion that, ever: since the birth of air-breathing life, some $30,000,000$ or $40,000,000$ years ago, let us say, the interplay of these agencies of supply and depletion has been so balanced that neither fatal excess nor fatal deficiency has been permitted to cut short the history of the higher life.

The dangers of excess or deficiency of the other constituents of the air are, indeed, less narrow when named in percentages, but they are scarcely less real in theoretical possibility.

The well-being of life is hemmed in between a suitablis proportion of moisture in the air dependent on a competent area of water-surface to supply it, on the one hand, and a diluvial excess of water, on the other. Universal deluges and universal deserts would alike be disastrous. A few thousand feet more of water-depth or a few thousand feet less would alike seriously restrict the class of life to which we belong.

In even a more serious way the habitability of the earth is conditioned on a narrow range of mean temperature-a range, roundly speaking, of $100^{\circ}$ Centigrade. This is scarcely 5 per cent. of the range of natural temperatures on the earth, and a still smaller per cent. of the range of temperatures in the heavens. A few miles above us and a few miles below us fatal temperatures prevail. It is profoundly significant that the thermal states of the narrow zone of life on the face of the earth should have been kept within so close variations as to permit the millions of species forming the great genealogical lines leading up from the primitive types to have perpetuated their lineages in unbroken continuity for such ages, while the prevalent temperatures a few miles above them or a few miles below them, as well as in space generally, would have been fatal. While the necessary heat is dependent on the sun, this control of temperature seems to have been intimately related to the atmosphere, and is a further index of its specially critical functions.

To appreciate the full significance of the control of life conditions within these narrow limits when the possibilities were so free and so wide, there is need for some tangible index of the time, but there are at present no means for the close measure of the grologic ages, merely rough estimates of the order of magnitude. I ife was far advanced when a readable record first began to be made; but yet, since that record began, at least ioo, ono feet of sedimentsnot to choose the largest estimates-have been laid down by the slow methods of wash from the land and lodgment in the basins. The estimate of the years thus represented has been put variously from $50,000,000$ to $100,000,000$, with, indeed, higher figures as well as lower. Merely to scale roughly the order of magnitude, and without pretence of accuracy, let us take the midway figure of $75,000,000$ years as represcntative. Let this be divided into fifteen periods of 5 ,000,000 vears each, and these will roughly represent the technical "periods" of geologists. By this rough scale we may space out such of the great events as we need now note.

Slight and changeable excesses of evaporation over precipitation and the reverse prevail widely, but only intense and persistent aridity gives rise to thick deposits of salt, gvpsum, and other evaporation products over large areaswith perhaps some exceptions-for in nearly all large natural basins the area that collects rainfall is notabiy larger than the closed basin within it that alone can retain water for continuous evaporation. It is, therefore, fairly safe to infer clear skies and pronounced aridity when beds of salt and gypsum occur over large areas, especially if accompanied by appropriate physical characters and by such types of life only as tolerate high salinity or show pauperisation, or by a total absence of life.

Now extensive deposits of salt and gypsum are found in the Salt Range of India, in strata of the Cambrian period, the earliest of the fifteen that make up our rough scale of $75,000,000$ years. Because these lie so near the beginning of the geologic record, they afford a singularly instructive insight into the conditions of the atmosphere well back toward its primitive state. They challenge at once the view that in those early ages the earth was swaddled by a dense vaporous atmosphere from pole to pole; for under such a vaporous mantle a great desert tract in India would be scarcely credible.

NO. 2 I06, VOL. 83]
If we come forward in time two periods, to the deposits of the Silurian stage, we find that, underlying the basin of the St. Lawrence in New York and westward, there stretch great sheets of salt and gypsum, many thousand squars miles in extent. These beds are accompanied by complete barrenness of life in some parts, by pauperisation of life in other parts, by selections of life according to tolerance of salinity in still other parts, and by harmonious physical characters, all of which combine to add strength to the interpretation. All these imply a degree of aridity approaching desert conditions in what is now the well-watered region of our Great lakes. These signal facts join those of the Salt Range of India of earlier date in challenging the former conception of a universal envelope of vapour and cloud in all those early times.

In the next period there are formations that have been interpreted as implying desert conditions, but perhaps on less firm grounds, and we pass on to certain stages in the Sub-Carboniferous period next following, wherein beds of salt and gypsum are found in Montana, Michigan, Nova Scotia, and Australia, which imply like climatic conditions. If we pass on to the Permian and Triassic periods, near the middle of the geologic series, beds of salt and gypsum are phenomenally prevalent on both the eastern and western continents, reaching through surprising ranges of latitude. The relative paucity, as well as the peculiar characteristics of the life of those times, seems equally to imply vicissitudes of climate in which scant atmospheric moisture was a dominant feature. There seems no tenable way to interpret these remarkable facts of the middle periods except by assuming an even greater prevalence of aridity than obtains at the present time. So, at times in the later periods, but at times only, the stratigraphic record implies atmospheres as arid as that of to-day. not everywhere, indeed, but in notable areas and in certain horizons.

These and other significant facts of consonant import form one group of phenomena.

If on the other hand, the record be searched for facts of opposite import, they will come easily to hand. Starting near the beginning of the record, it is even more easy to find stages abounding in evidences of prevailing humidity of great uniformity of climate, and of most congenial lifeconditions reaching through wide ranges of latitude. If we rested on this selection alone, the old view would he abundantly sustained, but the strata bearing evidences of aridity lie between these. Combining the two sets of facts. aridity lie between these. Combining the two sets of fact. the very earliest stages of the distinct life-record onward. there have been times and places of pronounced aridity much as now, or even more intense, while at other times, intervening between these, more humid and uniform conditions prevailed.

This conception grows in strength as we turn from atmospheric states to prevailing temperatures. The body of scientific men have rarely been more reluctant to accept any interpretation of geologic phenomena than that of recent general glaciation on the lowlands of Europe and America in mid-latitudes when that view was first advanced by Louis Agassiz. With the conception of former pervasive warmth then prevalent, it seemed bevond belief that great sheets of ice could have crept over large portions of the habitable parts of Europe and North America some thousands or tens of thousands of years ago. Belief in this was made easier, however, by the view also then prevalent wat the earth had been greatly cooled in the progress of the ages, that the atmosnhere had been much denleted by the formation of coal, of carbonates, and of oxides, that the formation had been rcduced by hydration and entrance into the earth, and that thus a stage had been reached that made possible an epoch of depressed temperature and of glaciation. The Ice age, thus theoretically associated, came to be widely regarded as but the first stage in a series of secular winters destined to lead on to the total refrigeration of the earth. This view was abetted bv the theorv of a cooling sun. The depleting and the cooling processes were regarded as inevitably progressive and the final doon of the earth as thus foreshadowed in the near future, geologically speaking.

But opinion was scarcely more than adjusted to this view when the geologists of Australia, of India, and of South Africa, severally and independently, and later those of South America, presented evidences of former glaciation 
over extensive areas in those low latitudes. The typical marks of glaciation were, indeed, traced even up to and a little across the tropical circles from the south, in Australia, and from the north, in India. Moreover, all these were reported from strata of Permian or late Carboniferous simes, i.e. from the sixth or seventh of the technical "periods." For a score of years the body of geologists, not in immediate contact with the evidence itself, doubted the interpretation, but the growing evidence grew at length to be utterly irrefutable. There seems no rational escape from the conclusion that mantles of ice covered large areas in the peninsula of India, in Australia, in the southern part of Africa, and in South America, close upon the borders of the tropics, at a time roundly hali-way back to the beginning of the readable record of life.

On the basis of similar evidence, Strahan and Reusch have announced glacial beds in Norway at a horizon much lower but not closely determinate. Willis and Blackwelder have described glacial deposits of early Cambrian age in the valley of the Yangtse, in China, in latitudes so loxv as $31^{\circ}$. Howchin and David have described glacial formations of similar age in Australia. In the last two cases the glacial beds lie below the strata that bear the Cambrian trilobites; in other words, they lie at the very bottom of the fossil-bearing sediments, fifteen periods back, or $75,000,000$ years ago on our rough scale. Prof. Coleman has offered what he deems good evidence of glaciation much farther back at the base of the Huronian, in Canada, but some scepticism as to its verity has yet to be overcome. ${ }^{1}$

Even more pointedly than the epochs of aridity do these early epochs of glaciation seem incompatible with the view of a hot earth universally wrapped in a vaporous mantle in early times. They favour the alternative view of merely temporary localised intensifications of climate which life was able repeatedly to survive. This seems to warrant the belief that life may survive similar intensifications again and again in the future.

At present polar and alpine glaciation are contemporaneous with aridity. There are reasons for thinking that the past glaciations and aridities were in some similar way correlated, and that they cooperated to give vicissitude to the climates of certain geologic epochs. The known epochs of glaciation, however, are fewer than those of aridity.

On the other hand, at several stages, as already noted, abundant life, bearing all the evidences of a warmtemperate or subtropical character, flourished in high latitudes. In Greenland, Spitsbergen, and other Arctic islands, are found the relics of life not known to be able to live except under conditions of genial warmth. These imply former subtropical conditions where now only frigidity reigns.

In the light of these contrasted climatic states of aridity and glaciation on the one hand, and of uniformity and geniality in high latitudes on the other, intervening between one another, we seem now forced to the conception of profound climatic alternations, extending over the whole stretch of known geologic time. Concurrent with these alternations, there may, perhaps, have been variations in the constitution, as there certainly were in the condition, of the atmosphere.

If we turn to the relations of the waters and the land, an analogous oscillating history presents itself. This was possibly connected causally with the climatic oscillations. At no time in the history recorded by clear geologic testimony is there proof of the absence of land, and certainly at no time is there a hint of the absence of an ocean, whatever theoretic views may be held of the earliest unknown stages.

The progress of inquiry seems to force the conviction that the land area in the earliest stages of good record was quite comparable to that of the present time, both in its extent and in its limitations. Following down the history, the land area seems at certain times to have been larger than now, while at other times it was smaller. There appears to have been an unceasing contest between the agencies that made for the extension of the land and the agencies that made for the extension of the sea. Whilo each gained temporarily on the other, complete victory

I I Later evidence has removed this from many minds, including that of the speaker.

No. $21 \mathrm{c} 6$, vor. 8.31 never rested with either. From near the beginning of the readable record there appears to have been an unbroken continuity of land life, and, from a like early stage, an unbroken continuity of marine life. Probably the history of both goes back unbroken into the undeciphered eras which precede the readable record, and no one to-day can safely affirm the precedence of either over the other, either in time or in genesis, whatever his theoretic leanings may be.

Among the agencies that may be assigned for the extension of the land are those that deform the body of the earth, deepening its basins and drawing off the waters, while other portions are protruded and give renewed relier and extent to the land. Among the agencies that make for the extension of the sea are the girdling of the waves about the borders of the land, and the decay and wash of land surface, which is thus brought low at length and covered by the advancing waters. If the deformation of the earthbody were held in abeyance for an indefinite time, the lowering of the land, the filling of the basins, and the spreading of the sea would submerge the entire land surface and bring an end to all land life. Great progress in such sea-transgressions appears to have been made again and again, until perhaps half the land was submerged, but before land life was entirely cut off, or even very seriously threatened, a regenerative movement in the body of the earth intervened, the land was again extended, and the sea again restricted. Here then, also, there has been a reciprocal movement, which, while it has brought alternate expansions of land life and of sea life, has, notwithstanding, permitted the preservation of both, and thus maintained the continuity of the two great divisions of life.

It appears, thus, that in each of the great groups of terrestrial conditions upon which life is dependent, there has been, through the known ages, vast as they are, an oscillatory movement which has brought profound changes again and again, but has never permitted any of the disasters threatened in these movements to go far enough to compass the universal extinction of life. These reciprocal movements appear to be dependent upon a balancing of the action of agencies that is scarcely less than a law of equilibrium. It is not too much to regard this as a regulative system. A clear insight into the agencies of this regulative system is rather a task of the future than an attainment of the present, and I can only offer tentative hints of what may prove to be its main factors, and beg of you to accept them with due reserve.

The preservation of the land against the incessant encroachments of the waters seems probably due to a periodic deformation of the earth-body dependent on internal dynamics not yet well understood, at least not yet demonstrated to general satisfaction. The body of the earth feeds its atmosphere through volcanic and other means. How far this is merely a return of what has been absorbed earlier it is not prudent here to say, as opinion is not harmonious on this, and the evidence is as yet uncertain. Much depends on the constitution of the earth's interior, and that in turn hinges on its mode of origin. Perhaps it will be agreed generally that feeding from the interior is one of the sources of supply which offsets the depletion of the atmosphere caused by its union with earth substance, in short, that the earth-body gives out as well as takes in atmospheric material. Important or unimportant as this may be, it is not apparent that there is in it any automatic balancing suited to control the delicate adjustments requisite for continuity of life. The ocean acts as an important regulator by alternately absorbing and giving out the atmospheric gases as required by the state of equilibrium between the water and the air. This action is automatic, but has its limitations and peculiarities, and does not seem wholly adequate. If we are able to name such an adequate automatic action at all at present, it probably lies in the molecular activities of the terrestrial and solar atmospheres, and in the relations of these to the gravitative powers of the earth and the sun.

If analysis of the molecular action of the outer atmosphere be pushed to its logical conclusions, it leads to the ronception of supplementary atmospheres, in part orbital, filling, in an attenuated way, the whole sphere of the earth's gravitative control. A similar study of the sun's atmosphere suggests a similar supplementary extension, and thi extended portion surrounds and embraces the earth's 
atmosphere. Under the laws of molecular activity these two atmospheres must be interchanging molecules at rates dependent on the conditions of equilibrium between them. It is reasonable that an excess in the earth's atmosphere should cause it to feed out into the sun's sphere of control more than it receives, and that a deficiency in the earth's atmosphere should cause more feeding in from the sun's supplementary atmospheres than the earth gives out. If this conception be true and be efficient, the maintenance of the delicate atmospheric conditions required for the continuity of life is automatically secured. The failure of our atmospheric supply is thus made to hang, not simply on the losses and gains at the earth's surface, but on the solar interchange, and hence on the solar endurance.

The sun is giving forth daily prodigious measures of energy. The endurance of the sun is not, however, merely a question of unrequited loss, for it gains energy and substance daily as well as loses, and, so far as present knowledge goes, its gain is greatly inferior to its loss. So long as the heat of the sun was supposed to be dependent on ordinary chemical changes, or on the fall of meteorites, or on self-contraction, an activity adequate for terrestrial life could only be estimated at a few million years. But recent discoveries in radio-activity have revealed sources of energy of an extremely high order. In the light of these the forecast of the sun's power to energise the activities of the atmosphere dependent on it, and to warm the earth, is raised to an indeterminate order of magnitude.

If we may thus find grounds for a complacent forecast in reciprocal actions on the earth and in reciprocities between the earth and the sun, are we free from impending dangers in the heavens without?

Present knowledge points to one tangible possibility of disaster-collision with some celestial body, or close approach to some sun or other great mass, large enough to bring disaster by its disturbing or disruptive effects. Within the solar system, the harmonies of movement already established are such as to give assurance against mutual disaster for incalculable ages. Comets pursue courses that might, theoretically at least, bring about collision, but do not appear usually to possess masses sufficient to work complete disaster to the life of the earth even should collision occur, whatever local disaster might follow at the point of impact. The motions of the stars, however, lie in diverse directions, and collisions and close approaches between them are theorctically possible, if not probable, or even inevitable. There are also in the heavens nebulæ and other forms of scattered matter, and doubtless also dark bodies, which may likewise offer possibilities of collision. The appearance of new stars flashing out suddenly and then gradually dying away suggests the actual occurrence of such events. It has been even corceived that the close approach of suns is one of the regenerative processes by which old planetary systems are dispersed and new systems are brought into being. One phase of the planetesimal hypothesis is built on this conception, and postulates the close approach of some massive body to our ancestral sun as the source of dispersion of a possible older planetary system, and the generation of the nebulous orbital conditions out of which our present system grew. However this may be, it must be conceded that in collision and close approach lie possibilities, if not probabilities, of ultimate disaster to the solar system and to our earth. But here, as before, the vital question lies in the time element. How imminent is this liability? 'The distances between stars are so enormous that, though they move diversely, the contingencies of collision or disastrous approach are remote. Nothing but rough computations based on assumptions can be made, but these make disaster to a given sun or system fall, on the average, only once in billions of years. There is no star the nearness of which to us, or the direction of motion of which is such as to threaten the earth at any specific period in the future. There is only the general theoretical possibility or probability. While, therefore, there is to be, with little doubt, an end to the earth as a planet, and while, perhaps, previous to that end conditions inhospitable to life may be reached, the forecast of these contingencies places the event in the indeterminate future. The geologic analogies give fair grounds for anticipating conditions congenial to life for millions or tens of millions of years to come, not to urge the even larger possibilities.

But congeniality of conditions does not ensure actual NO. 2 I06, VOL. 83] realisation. There arise at once questions of biological adaptation, of vital tenacity, and of purposeful action. Appeal to the record of the animal races reveals in some cases a marvellous endurance, in others the briefest of records, while the majority fell between the extremes. Many families persisted for millions of years. A lons career for man may not, therefore, be denied on historical grounds, neither can it be assured; it is an individual race problem; it is a special case $f$ the problem of the races in the largest sense of the phrase.

But into the problem of human endurance two new factors have entered, the power of definite moral purpose and the resources of research. No previous race has shown clear evidence that it was guided by moral purpose in seeking distant ends. In man such moral purpose has risen to distinctness. As it grows, beyond question it will count in the perpetuity of the race. No doubt it will come to weigh more and more as the resources of destructive pleasure, on the one hand, and of altruistic rectitude, on the other, are increased by human ingenuity. It will become more critical as the growing multiplicity of the race brings upon it, in increasing stress, the distinctive humanistic phases of the struggle for existence now dimly foreshadowed. It will, beyond question, be more fully realised as the survival of the fittest shall render its verdict on what is good and what is evil in this realm of the moral world.

But, to be most efficient, moral purpose needs to be conjoined with the highest intelligence, and herein lies the function of research. None of the earlier races made systematic inquiry into the conditions of life, and sought thereby to extend their careers. What can research do for the extension of the career of man? We are witnesses of what it is beginning to do in rendering the forces of nature subservient to man's control and in giving him command over the maladies of which he has long been the victim. Can it master the secrets of vital endurance, the mysteries of heredity, and all the fundamental physiological processes that condition the longevity of the race? The answer must be left to the future, but I take no risk in affirming that when ethics and research join hands in a broad and earnest endeavour to compass the highest development and the greatest longevity of the race, the era of humanity will really have besun.

\section{FORTHCOMING BOOKS OF SCIENCE.}

\section{Agriculture.}

D. Appleton and Co.-The Story of Sugar G. T. Surface, illustrated. Constable and Co., Ltd.--Soils and Manures, J. A. Murray. Duckworth and Co.-Agricultural Bacteriology, J. Percival, illustrated; and a new edition of Agricultural Botany, J. Percival, illustrated. The Gresham Publishing Company. - The Standard Cyclopedia of Modern Agriculture and Rural Economy, vols. viii. to xii., iliustrated. Macmillan and Co." Ltd.Barthel's Method for the Examination of Milk and Milk Products, translated by $W$. Goodwin; Improvement of Wheat and other Cereals, Prof. R. H. Biffen.

\section{Anthropology.}

Macmillan and Co., Ltd.-Totemism and Exogamy: a Treatise on certain Ancient Forms of Superstition and Society, Dr. J. G. Frazer, with maps, 4 vols. Methuen and Co.-The Negro in the New World, Sir H. H. Johnston, illustrated. Milner and Co., Ltd.--Prehistoric Man, J. McCabe, illustrated. Swan Sonnenschein and Co., Ltd. - Bushman Folk-lore, L. C. Lloyd, edited by Dr. G. M. Theal, illustrated; History and Ethnography of South Africa before 1795 , Dr. G. M. Theal, vol. iii., the Dutch Portuguese, Hottentots and Bantu to September, 1795.

\section{Biology.}

John Bale, Sons and Danielsson, Ltd.-Lectures on Biology, Dr. C. Thesing, new edition, illustrated. G. Bell and Sons.- The Care of Trees in Lawn, Street and Park, B. E. Fernow, illustrated. W. Blackwood and Sons.The Sovereignty of the Sea, Dr. T. W. Fulton, illustrated. $R$. Culley.-In Nature's Nursery : a Book of Nature-study for Beginners, Rev. S. N. Sedgwick; The Young Fisher- 